\title{
Comparison of the remineralization effect of newly-developed fluoride agents according to the depth of early carious lesions
}

\author{
Mi-Ri Kim¹, Nan-Young Lee², Myeong-Kwan Jih², Ji-Woong Kim³ , Won-Seok Choi ${ }^{3}$, and Sang-Ho Lee ${ }^{2 \star}$ \\ ${ }^{1}$ Doctor of Dental Clinic, Woo-Ri Ai Kids Dental Clinic, Hwaseong, Republic of Korea \\ ${ }^{2}$ Professor, Department of Pediatric Dentistry, School of Dentistry, Chosun University, Gwangju, Republic of Korea \\ ${ }^{3}$ Resident, Department of Pediatric Dentistry, School of Dentistry, Chosun University, Gwangju, Republic of Korea
}

This study aimed to compare the re-mineralization effects of the new fluorine formulations of the $5 \%$ sodium fluoride adhesive film (NaF

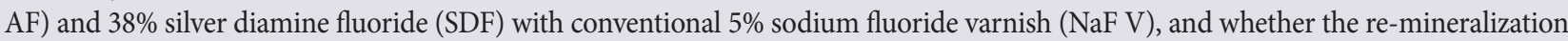
effect of each fluoride formulation is affected by the depth of the initial enamel caries. The re-mineralization effect of the SDF group was significantly greater than those of the $\mathrm{NaF} \mathrm{V}$ and $\mathrm{NaF}$ AF groups $(p<0.05)$. The $\mathrm{NaF} \mathrm{V}$ and $\mathrm{NaF}$ AF groups showed a significantly greater re-mineralization effect than did the control group (artificial saliva) $(p<0.05)$, and there was no difference between those two groups. Also, in the $\mathrm{NaF} \mathrm{V}$ and $\mathrm{NaF} A F$ groups, there was no significant difference in the degree of re-mineralization depending on the depth of the initial enamel caries, but in the SDF group, a significantly greater amount of re-mineralization was observed in deep lesions than in shallow lesions $(p<0.05)$. SDF is expected to expand the range of fluoride for the prevention and treatment of dental caries that were limited to initially shallow caries.

Key Words: Dental caries, Fluoride vanish, Sodium fluoride, Tooth remineralization

(c) This is an open-access article distributed under the terms of the Creative Commons Attribution Non-Commercial License (http://creativecommons.org/licenses/by-nc/4.0) which permits unrestricted noncommercial use, distribution, and reproduction in any medium, provided the original work is properly cited.

\section{Introduction}

치아우식증은 탈회와 재광화의 순환 균형이 무너져 초기의 가역적인 단계로부터 비가역적인 단계로 이행되는 동적인 과정 으로 정의된다. 따라서 초기 치아우식증은 법랑질 표면의 탈회 부위를 불소 등의 재광화 제제를 이용한 보존적인 처치로 원상 회복이 가능하다[1,2].

현재 전문가 불소도포법으로 가장 많이 사용하는 불소바니쉬 는 접착성이 좋은 송진 성분에 $5 \%$ 불화나트륨(sodium fluoride, $\mathrm{NaF})$ 을 포함하고 있는데, 다른 불소제제에 비해 도포방법이 간 단하고 삼킬 위험이 적어 안전하며 고농도의 불소를 치면에 잔
류시킬 수 있는 장점으로 인하여 치아우식증 예방 효과가 크다 [3]. 그러나 불소바니쉬는 맛이 좋지 않고 끈적거리며 타액에 의 해 쉽게 씻겨 내려간다는 점이 문제점으로 지적된다[4].

최근 위와 같은 문제점을 해결하기 위해 불소를 함유한 접착 필름(adhesive film, $\mathrm{AF}$ ) 형태의 새로운 전달시스템에 의한 불 소제제가 개발되고 있고 silver diamine fluoride (SDF)와 같은 액상형의 불소제제가 소개되고 있다. SDF는 2014년 미국 Food and Drug Administration의 승인을 받으면서 주목받기 시작한 불소제제로, 강력한 재광화 효과와 우식원성 세균에 대한 항균 작용을 특징으로 하며, 치아우식증의 예방은 물론 진행억제효 과를 가지고 있는 것으로 알려져 있다[5,6]. 접착 필름형 불소제

Received July 7, 2020; Revised July 31, 2020; Accepted August 2, 2020

*Corresponding author: Sang-Ho Lee, Department of Pediatric Dentistry. School of Dentistry, Chosun University, 303 Pilmun-daero, Dong-gu, Gwangju 61452, Republic of Korea.

Tel: +82-62-220-3865, Fax: +82-62-225-8240, E-mail: shclee@chosun.ac.kr 
제는 2013년 처음으로 문헌에 소개되었는데, 생체 안정성이 높 은 친수성 고분자인 polyvinyl alcohol (PVA)에 5\% NaF를 첨가 한 얇은 필름 형태의 불소제제로 실험실적, 임상적 연구를 통하 여 법랑질의 재광화 효과 및 지각과민증 감소 효과가 보고된 바 있다[7,8].

여러 연구에서 새로 개발된 불소제제들의 우식 치질에서의 재광화 효과를 보고하고 있으나 이들의 효과를 현재까지 가장 많이 사용되어 오고 있는 대표적인 불소바니쉬 제제인 $5 \%$ 불화 나트륨 바니쉬(NaF V)와 비교한 연구는 많지 않다. Delbem 등 [9]은 실험실적 연구에서 법랑질의 경우 $\mathrm{SDF}$ 가 $5 \% \mathrm{NaF}$ V에 비 해 탈회억제효과가 더 작다고 하였으며 Mohammadi와 Farahmand [10]는 유치를 대상으로 한 연구에서 $\mathrm{SDF}$ 와 $5 \% \mathrm{NaF} \mathrm{V는}$ 법랑질 탈회억제효과는 차이가 없으나 상아질에서는 $\mathrm{SDF}$ 가 효 과가 더 크다고 하였다. 이와 같이 불소제제의 법랑질에서의 재 광화 효과에 대한 실험실적 연구가 다양한 연구결과를 보여주 고 있는 이유에 대해 일부 학자들은 인공적으로 유도한 우식병 소의 깊이 차이에 기인하는 것으로 보고하고 있다[11]. 이와 같 은 연구는 법랑질에서 초기 치아우식병소의 깊이가 불소제제의 재광화 효과에 영향을 미칠 수 있음을 시사하나 아직까지 치아 우식증의 병소 깊이에 따른 불소제제의 재광화 효과에 대한 연 구는 많지 않아 단언하기는 어렵다.

따라서 이 연구에서는 기존의 불소바니쉬 제제와 새로 개발 되어 소개되고 있는 $38 \% \mathrm{SDF}$ 와 $5 \% \mathrm{NaF} \mathrm{AF}$ 의 초기 우식병소에 서의 재광화 효과를 기존의 $5 \% \mathrm{NaF} \mathrm{V}$ 와 비교하고 또한 이와 같 은 재광화 효과가 병소 깊이에 따라 영향을 받는지에 대해 알아 보고자 하였다.

\section{Materials and Methods}

\section{실험 재료}

이 연구에서는 탈회된 법랑질의 재광화를 위한 불소제제로 38\% SDF (Advantage Arrest; Elevate Oral Care, West Palm Beach, FL, USA)와 저자들이 실험실에서 제조한 $5 \% \mathrm{NaF} \mathrm{AF}$ 을 사용하였으며 이들의 효과를 비교하기 위한 기준 군으로 5\% NaF V (MI Varnish; GC Co., Tokyo, Japan)를 사용하였다.

$5 \% \mathrm{NaF} \mathrm{AF}$ 은 실험실에서 다음과 같은 공정에 의해 제조되었 다. 먼저 기저제로 PVA (F-17a; Sigma-Aldrich Inc., St. Louis, MO, USA) 10.0 g과 polyacrylic acid (Sigma-Aldrich Inc.) $5.0 \mathrm{~g}$ 을 $85 \mathrm{~g}$ 의 증류수에 용해시킨 후 가소제로 polyethylene glycol $3.0 \mathrm{~g}$ 을 첨가하여 $85^{\circ} \mathrm{C}$ 에서 2 시간 동안 교반하였다. 여 기에 $1.0 \mathrm{~g}$ 의 NaF와 점증제인 carboxyvinyl polymer (SigmaAldrich Inc.) $1.5 \mathrm{~g}$, 계면활성제인 poloxamer-407 (Sigma-
Aldrich Inc.) $1.2 \mathrm{~g}$ 을 첨가하고 수분 함량이 7\%-10\% 정도 될 때까지 계속적으로 교반하였다. 이렇게 가교화 과정을 거친 PVA-NaF 용액을 편평한 유리판에 부은 후 $20 \mu \mathrm{m}$ 의 균일한 두 께로 맞추어진 필름 형성기기에서 roller를 구동시켜 필름을 사 출하였다. 높은 점주도의 액상으로 사출된 필름은 $60^{\circ} \mathrm{C}$ 에서 24 시간 동안 건조하여 고형화하였다.

\section{연구 방법}

\section{시편제작}

우식이나 구조적 결함이 없는 소의 전치를 가로 $5.0 \mathrm{~mm}$, 세 로 $5.0 \mathrm{~mm}$, 높이 $5.0 \mathrm{~mm}$ 크기가 되도록 저속 핸드피스로 절단 한 후 직경 $10.0 \mathrm{~mm}$, 높이 $10.0 \mathrm{~mm}$ 크기의 아크릴 주형에 법 랑질 표면이 노출되도록 매몰하였다. 매몰된 시편의 법랑질 표 면을 400, 800, 2400, 4000 grit의 silicon carbamide paper (RB 204 METPOL-1; R\&B Inc., Daejeon, Korea)를 이용하여 단계적으로 표면을 활택, 연마하였다. 지름 $5.0 \mathrm{~mm}$ 의 원형 스 티커를 법랑질 표면에 부착하고 nail varnish를 도포한 후 스티 커를 떼어내어 정상 법랑질과 탈회시킬 영역을 규격화하였다. 깊이가 다른 우식병소를 유발하기 위해 시편을 무작위로 2 개의 군으로 나누어 배분하고 한 군(얕은 초기 우식병소)의 시편은 탈 회용액 (2.2 mM Ca( $\left.\mathrm{NO}_{3}\right)_{2}, 2.2 \mathrm{mM} \mathrm{KHxPO}$, $50 \mathrm{mM}$ Macetic acid, $\mathrm{pH}$ 4.5)에 24시간 동안 침전시켜 탈회하였고, 다른 군(깊 은 초기 우식병소)의 시편은 72 시간 동안 침전시켰으며 탈회용 액은 매 24 시간마다 3 회에 걸쳐 새 것으로 교체했다. 시편을 담 은 탈회용액은 $37^{\circ} \mathrm{C}$ 항온기에 보관하였다.

\section{시편의 분류}

탈회된 시편들을 생리식염수로 세척 후 건조시킨 상태로 QLF-D (All in one Bio Co., Seoul, Korea)를 사용하여 촬영 한 후 시편의 이미지를 저장하고 QA2 분석프로그램(All in one Bio Co., Seoul, Korea)을 통해 탈회 정도를 정상 치질과 비교 한 형광색조대비차 $(\Delta \mathrm{F})$ 를 측정하였다. 측정한 $\Delta \mathrm{F}$ 를 기준으로 초기 치아우식병소를 얕은 병소 $(\Delta \mathrm{F}>-25)$ 와 깊은 병소(-25> $\Delta \mathrm{F}>-50)$ 로 분류하고, 각각의 시편을 다시 적용할 불소제제의 종류에 따라 대조군(artificial saliva), $\mathrm{NaF} \mathrm{V}, \mathrm{NaF} \mathrm{AF}, \mathrm{SDF}$ 의 4 개의 군으로 나누어 각각 15 개씩 배분하였다. $\Delta \mathrm{F}$ 를 기준으로 한 초기 우식병소의 깊이 분류는 QLF-D 제조회사의 가이드라인을 참고하였으며 Alammari 등[12], Kim 등[13]의 선행 연구를 근 거로 기준값을 설정하였다.

\section{불소제제를 이용한 재광화}

세 가지 불소제제의 재광화 효과를 비교하기 위해 각각의 군 
에 따라 다음과 같이 불소제제를 적용했다.

대조군은 탈회된 시편에 어떠한 제제도 적용하지 않은 상태로 인공타액 $\left(0.38 \mathrm{~g} \mathrm{NaCl}, 0.21 \mathrm{~g} \mathrm{CaCl}_{2} 2 \mathrm{H}_{2} \mathrm{O}, 1.11 \mathrm{~g} \mathrm{KCl}, 0.74 \mathrm{~g}\right.$ $\mathrm{KH}_{2} \mathrm{PO}_{4}, \mathrm{pH} 7.0$ )에 침잠시켜 $37^{\circ} \mathrm{C}$ 항온기에서 7일간 보관하였 으며 인공타액은 24 시간 마다 교체했다. $\mathrm{NaF} \mathrm{V군은} \mathrm{각} \mathrm{시편의}$ 탈회된 부분에 $5 \% \mathrm{NaF} \mathrm{V}$ 를 전용 브러쉬를 이용해 도포하고 환 자의 구강 내 적용하는 시간을 고려해 4 분간 위치시켰다. $\mathrm{NaF}$ $\mathrm{AF}$ 군은 치면에 잘 접착할 수 있도록 마이크로브러쉬로 인공타 액을 시편 표면에 바른 후 가로 $5.0 \mathrm{~mm}$, 세로 $5.0 \mathrm{~mm}$ 크기의 $\mathrm{AF}$ 을 접착시켜 4분 동안 유지했다. $\mathrm{SDF}$ 군은 전용 어플리케이터 를 이용해 도포하고 압축공기로 가볍게 건조시키고 4 분간 유지 했다. 불소제제를 도포한 시편들은 대조군과 동일한 방법으로 보관하였다.

\section{Micro-CT를 이용한 법랑질의 재광화도 평가}

Micro-CT (Quantum GX $\mu \mathrm{CT}$ imaging system; PerkinElmer, Hopkinton, MA, USA)를 이용하여 불소제제 도포 전 과 도포 7일 후의 시편을 단층촬영하였다. X-광선은 $90 \mathrm{kV}$ 와 $88 \mathrm{~mA}$ 수준으로, 그리고 field of view는 $10 \mathrm{~mm}$ 로 각각 설정 하였다. CT imaging은 Quantum GX 내에 탑재된 3D Viewer (PerkinElmer, Hopkinton, MA, USA)를 통해 시각화하였다. 스 캐닝 후, 영상분할(image segmentation)은 Analyze software 12.0 (AnalyzeDirec; Overland Park, KS, USA)을 이용하였으 며 이미지 노이즈 감소와 3차원에서 디테일을 보존하기 위해 영 상 시리즈를 'Spatial filter' 모듈을 사용하여 median filter로 필 터링하였다.

무기질 밀도 변화량 측정: 얻어진 이미지들은 Quantum GX $\mu \mathrm{CT}$ imaging system 내의 기본 소프트웨어인 Simple viewer (PerkinElmer)를 이용하여 법랑질 표면 및 각 단층에서 무기질 밀도 값(hounsfield unit value, HUV)을 측정하여 재광화 전후 의 무기질 밀도의 변화량 $(\Delta \mathrm{HUV})$ 을 기록했다. 무기질 밀도 측정 은 동일한 조사자가 각 시편당 3회씩 시행하여 그 평균값을 계 산하였다.

정상 수준으로 재광화된 법랑질의 부피 측정: 재광화 전후 에 촬영한 영상은 Quantum $\mathrm{GX} \mu \mathrm{CT}$ imaging system 내에 탑 재된 3D Viewer를 이용해 분석을 시행했다. 먼저 Analyse의 ‘Oblique Sections' 기능을 이용하여 영상 자료들을 수동으로 재배치하여 치아의 표준 관상면, 시상면 및 수평면을 시각화하 였다. 다음 객체 추출 및 연결된 구성 요소 레이블링을 사용하여 치아의 영역이 각 슬라이스에서 식별되게 한 후 부피를 측정하 고자 하는 관심부위(region of interest)에 해당하는 정상 법랑질 의 역치를 설정하고 surface rendering을 시행하여 3차원 이미 지를 만들고 이를 중첩하여 무기질 밀도가 정상 법랑질 수준으
로 회복된 부피 $\left(\mathrm{mm}^{3}\right)$ 를 측정하였다.

\section{주사전자현미경(SEM)을 이용한 법랑질 표면구조 분석}

SEM (JEOL JSM-840A, JEOL Co., Akishima, Japan)을 이용 하여 재광화 전후의 법랑질 표면의 미세구조를 관찰하였다. 진 공 데시게이터를 이용하여 시편들을 건조시킨 후 Ion sputter (E-1030; Hitachi, Tokyo, Japan)로 백금 코팅을 80초간 시행 했다. 백금 코팅된 시편은 카복테이프를 이용해 시료대 위에 고 정시키고 10,000 배 배율에서 관찰했다.

\section{통계분석}

실험 결과는 PASW Statistics for Windows, Version 18.0 (SPSS Inc., Chicago, IL, USA)를 이용하여 통계분석하였다. Shapiro-Wilk test를 시행하여 정규성을 검정하고 KruskalWallis test를 통해 각 군간 차이를 비교하였으며, Mann-Whitney U-test와 Bonferroni correction으로 사후검정을 시행하였 다 $(p<0.05)$.

\section{Results}

\section{법랑질 재광화 정도 평가}

\section{무기질 밀도 변화량( $\Delta \mathrm{HUV})$ 비교}

각 시편에서 불소제제를 이용한 재광화 전후의 무기질 밀도 변화량( $\triangle \mathrm{HUV})$ 을 측정하고, 불소제제의 종류와 병소 깊이에 따 른 차이를 비교, 평가하였다. 불소제제의 종류에 따른 재광화 전후의 $\triangle \mathrm{HUV}$ 는 $\mathrm{SDF}$ 군에서 121.38 로 가장 큰 반면, 대조군에 서 23.73로 가장 작게 나타났다( $p<0.05) . \mathrm{NaF} \mathrm{V}$ 군과 $\mathrm{NaF} \mathrm{AF}$ 군은 대조군에 비해 더 많은 무기질 밀도의 증가를 보였으나 $(p=0.012, p=0.031) \mathrm{NaF}$ 과 $\mathrm{NaF} \mathrm{AF}$ 군 사이에서는 무기질 밀 도 변화량의 차이는 없었다( $p=0.273)$ (Fig. 1).

우식병소 깊이에 따른 재광화 전후의 $\Delta \mathrm{HUV}$ 는 대조군, $\mathrm{NaF} \mathrm{V}$ 군, 그리고 $\mathrm{NaF} \mathrm{AF}$ 군에서는 우식병소 깊이에 따른 통계적으로 유의한 차이를 보이지 않았다. 그러나 $\mathrm{SDF}$ 군의 경우 얕은 우식병 소보다 깊은 우식병소에서 $\Delta \mathrm{HUV}$ 가 더 컸다 $(\mathrm{p}=0.008)$ (Table 1).

\section{정상 수준으로 회복된 법랑질의 정량적 평가}

Micro-CT 촬영을 통해 출력된 각 단층 영상에서 탈회 및 재 광화 양상을 시각화하기 위해 정상 법랑질은 붉은색, 탈회된 영 역은 초록색, 그리고 재광화에 의해 정상적인 무기질 밀도로 회 복된 부분은 남색으로 표시했다. 모든 군에서 재광화 후 정상 무 기질 밀도를 갖는 영역이 증가되는 양상을 보였다. 정상 수준의 법랑질로 재광화된 영역은 대조군에서 가장 작고, $\mathrm{SDF}$ 군에서 
가장 컸다. 이러한 양상은 얕은 병소와 깊은 병소에서 모두 동일 하게 관찰되었다(Fig. 2).

이와 같은 단층 영상들을 연결하여 3차원 영상으로 모형을 만들고, 재광화 후의 정상 법랑질의 무기질 밀도로 회복된 부피 $\left(\Delta \mathrm{mm}^{3}\right)$ 를 측정했다.

정상 무기질 밀도 수준으로 회복된 법랑질의 부피는 대조군 은 $0.52 \mathrm{~mm}^{3}$ 였다. $\mathrm{NaF} \mathrm{V}$ 군과 $\mathrm{NaF} \mathrm{AF}$ 군은 각각 $1.75 \mathrm{~mm}^{3}$, $2.65 \mathrm{~mm}^{3}$ 로 대조군에 비해 증가하였으나 $(p=0.015, p=0.006)$ 두 군 사이에는 유의한 차이를 보이지 않았다( $p=0.108) . \mathrm{SDF}$ 군 은 $4.34 \mathrm{~mm}^{3}$ 로 가장 많이 증가하였으며 다른 군들과 통계학적 으로 유의한 차이를 보였다( $p<0.05$, Fig. 3).

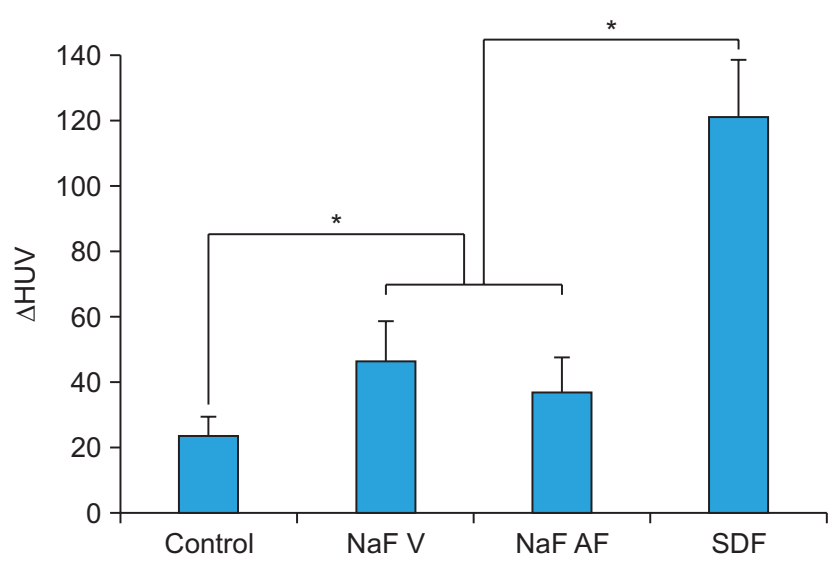

Fig. 1. Comparison of mineral density change ( $\Delta \mathrm{HUV})$ between groups. HUV, hounsfield unit value; $\mathrm{NaF} \mathrm{V}$, sodium fluoride varnish; $\mathrm{NaF}$ AF, sodium fluoride adhesive film; SDF, silver diamine fluoride. *Significantly difference $(p<0.05)$ by Mann-Whitney U-test.
대조군, $\mathrm{NaF} \mathrm{V군,} \mathrm{NaF} \mathrm{AF}$ 군에서는 얕은 우식병소와 깊은 우 식병소 간 정상 법랑질의 무기질 밀도로 회복된 부피가 통계적 으로 유의한 차이가 없었으나 $\mathrm{SDF}$ 군에서는 얕은 우식병소보다 깊은 우식병소에서 회복된 부피가 더 컸다 $(p=0.029)$ (Table 2).

\section{법랑질 표면의 미세구조 분석}

$\mathrm{SEM}$ 을 이용하여 탈회된 법랑질 표면과 재광화 후의 법랑질 표면의 미세구조를 10,000배 배율로 관찰하였다(Fig. 4, 5). 얕 은 우식병소는 법랑소주(enamel rod)가 노출되고 법랑소주 사 이의 결정구조가 파괴되어 불규칙한 표면을 보였다(Fig. 4A). 대 조군은 일부 법랑소주의 상방에 무정형 결정체가 침착된 상태 를 보이며 전체적으로 미세공과 미세균열 등 불규칙한 표면을

Table 1. Mean and standard deviation of mineral density changes $(\Delta \mathrm{HUV})$ between shallow and deep carious lesions

\begin{tabular}{cccc}
\hline Group & Lesion depth & \multicolumn{1}{c}{$\Delta$ HUV } & p-value \\
\hline Control & Shallow & $24.49 \pm 5.10$ & 0.741 \\
& Deep & $22.97 \pm 5.59$ & \\
$\mathrm{NaF} \mathrm{V}$ & Shallow & $51.59 \pm 17.65$ & 0.548 \\
& Deep & $41.54 \pm 7.71$ & \\
FAF AF & Shallow & $42.21 \pm 14.12$ & 0.573 \\
& Deep & $32.18 \pm 7.69$ & \\
SDF & Shallow & $105.88 \pm 3.28$ & $0.008^{*}$ \\
& Deep & $136.87 \pm 7.85$ & \\
\hline
\end{tabular}

Values are presented as mean \pm standard deviation.

HUV, hounsfield unit value; NaF V, sodium fluoride varnish; NaF AF, sodium fluoride adhesive film; SDF, silver diamine fluoride. ${ }^{\star}$ Significantly difference $(p<0.05)$ by Mann-Whitney U-test.

Shallow early carious lesion

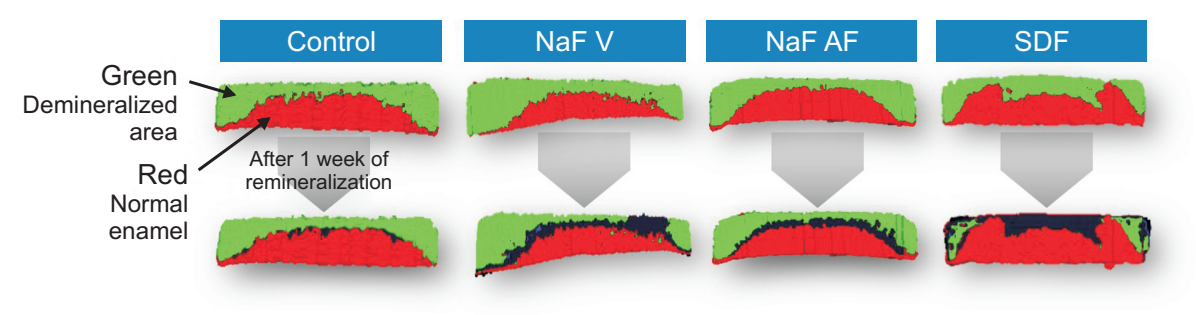

Deep early carious lesion

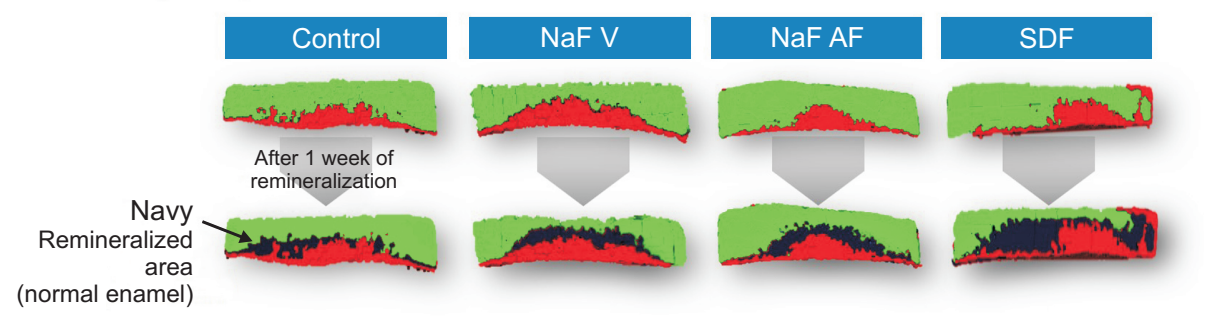

Fig. 2. Tomographic views of the remineralized area obtained from micro-CT. The remineralized zone that recovered to the normal enamel density (navy) of the SDF group was larger than that of the $\mathrm{NaF} \mathrm{V}$ and the $\mathrm{NaF}$ AF groups in both shallow and deep carious lesion. NaF V, sodium fluoride varnish; $\mathrm{NaF} \mathrm{AF}$, sodium fluoride adhesive film; SDF, silver diamine fluoride. 
보였다(Fig. 4B). NaF V군과 $\mathrm{NaF} \mathrm{AF}$ 군에서는 무정형 결정체가 법랑소주 상방에 침착되어 법랑소주와 융합된 모습을 보이고 있으며 대조군에 비해 더 부드러운 표면을 보였다(Fig. $4 \mathrm{C}, \mathrm{D}$ ). $\mathrm{SDF}$ 군은 무정형 결정체가 법랑소주 상방에 침착, 융합되어 탈

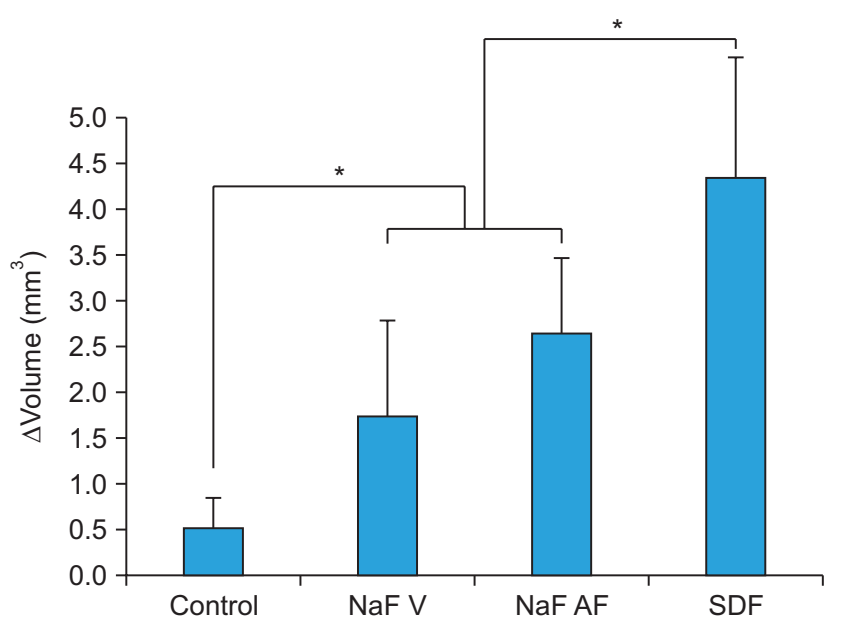

Fig. 3. Comparison of recovered volume $\left(\Delta \mathrm{mm}^{3}\right)$ to normal enamel density between the groups. NaF V, sodium fluoride varnish; $\mathrm{NaF} A F$, sodium fluoride adhesive film; SDF, silver diamine fluoride. ${ }^{\star}$ Significantly difference $(p<0.05)$ by Mann-Whitney U-test.
회된 표면의 대부분을 덮고 있으며 가장 부드러운 표면을 보였 다(Fig. 4E).

깊은 우식병소의 경우 법랑소주 사이의 결정구조가 광범위하 게 파괴되고 균열 등이 형성되어 표면애 불규칙하였다(Fig. $5 \mathrm{~A}$ ). 대조군은 무정형 결정체가 일부 법랑소주의 상방에 침착된 상 태를 보였으며 전체적으로 불규칙한 표면을 보였다(Fig. 5B).

Table 2. Comparison of mean volume $\left(\Delta \mathrm{mm}^{3}\right)$ recovered to normal enamel density between shallow and deep early carious lesions

\begin{tabular}{clcc}
\hline Group & Lesion depth & Volume $\left(\mathrm{mm}^{3}\right)$ & $\boldsymbol{p}$-value \\
\hline Control & Shallow & $0.65 \pm 0.35$ & 0.343 \\
& Deep & $0.39 \pm 0.15$ & \\
$\mathrm{NaF} \mathrm{V}$ & Shallow & $1.58 \pm 0.26$ & 0.730 \\
& Deep & $1.89 \pm 1.63$ & \\
$\mathrm{NaF} \mathrm{AF}$ & Shallow & $2.63 \pm 0.83$ & 0.886 \\
& Deep & $2.66 \pm 0.90$ & \\
$\mathrm{SDF}$ & Shallow & $3.32 \pm 0.52$ & $0.029^{*}$ \\
& Deep & $5.37 \pm 2.01$ & \\
\hline
\end{tabular}

Values are presented as mean \pm standard deviation.

$\mathrm{NaF} \mathrm{V}$, sodium fluoride varnish; NaF AF, sodium fluoride adhesive film; SDF, silver diamine fluoride.

${ }^{\star}$ Significantly difference $(p<0.05)$ by Mann-Whitney U-test.
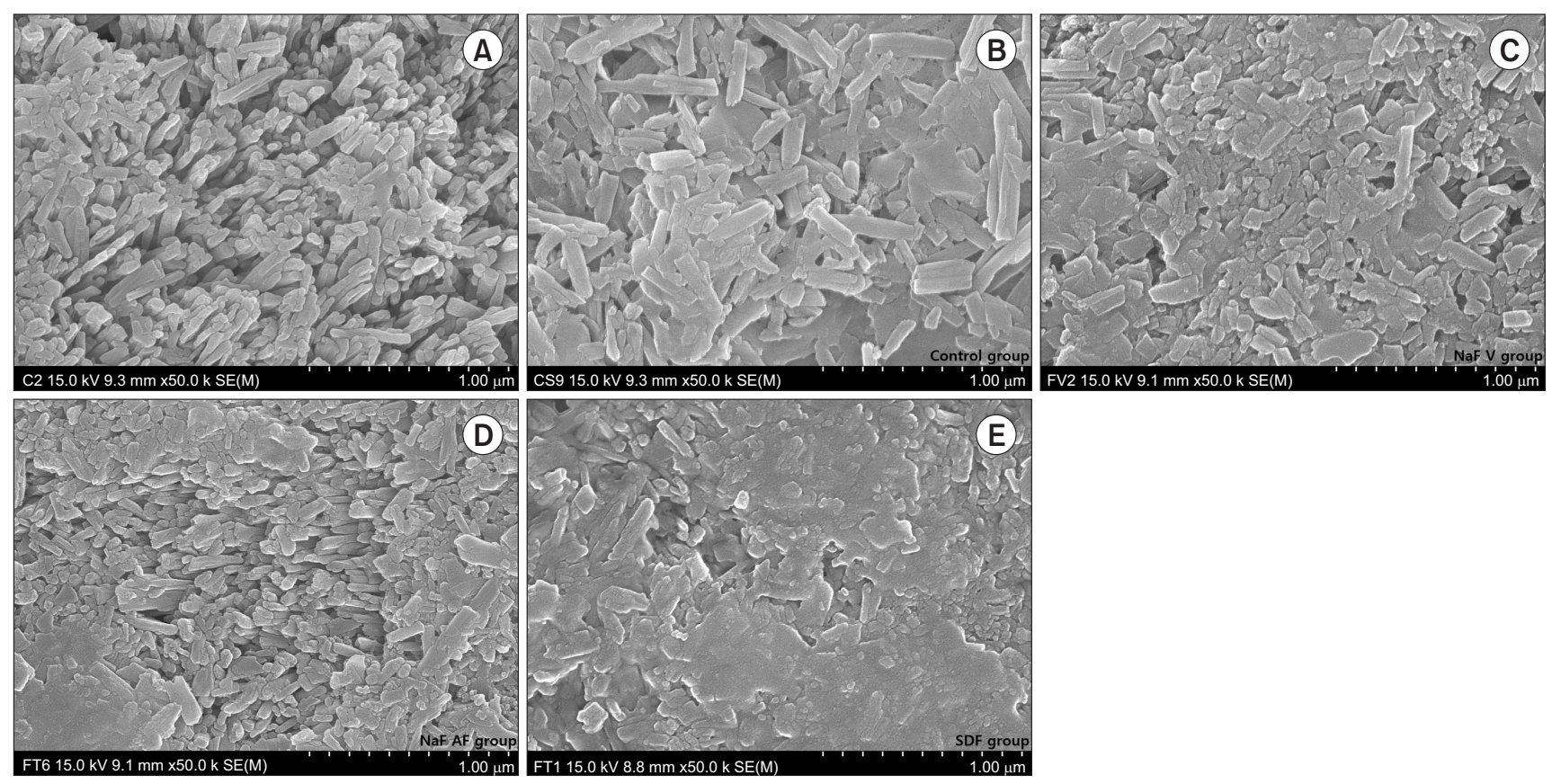

Fig. 4. The SEM images of microstructure of remineralized enamel surfaces in the shallow initial carious lesion $(\times 10,000)$. (A) Enamel rod was exposed and the crystal structure between the enamel rods was destroyed in the demineralized enamel specimen. (B) Amorphous crystals were deposited partially on enamel rod and micropores were present in the control group. (C, D) In NaF V and the NaF AF groups, amorphous crystals were deposited and fused with the enamel rods. The surface was less irregular than control group. (E) In SDF group, amorphous crystals were deposited and covered most of the deminerlized enamel. The surface was smoother than other groups. NaF V, sodium fluoride varnish; NaF AF, sodium fluoride adhesive film; SDF, silver diamine fluoride. 

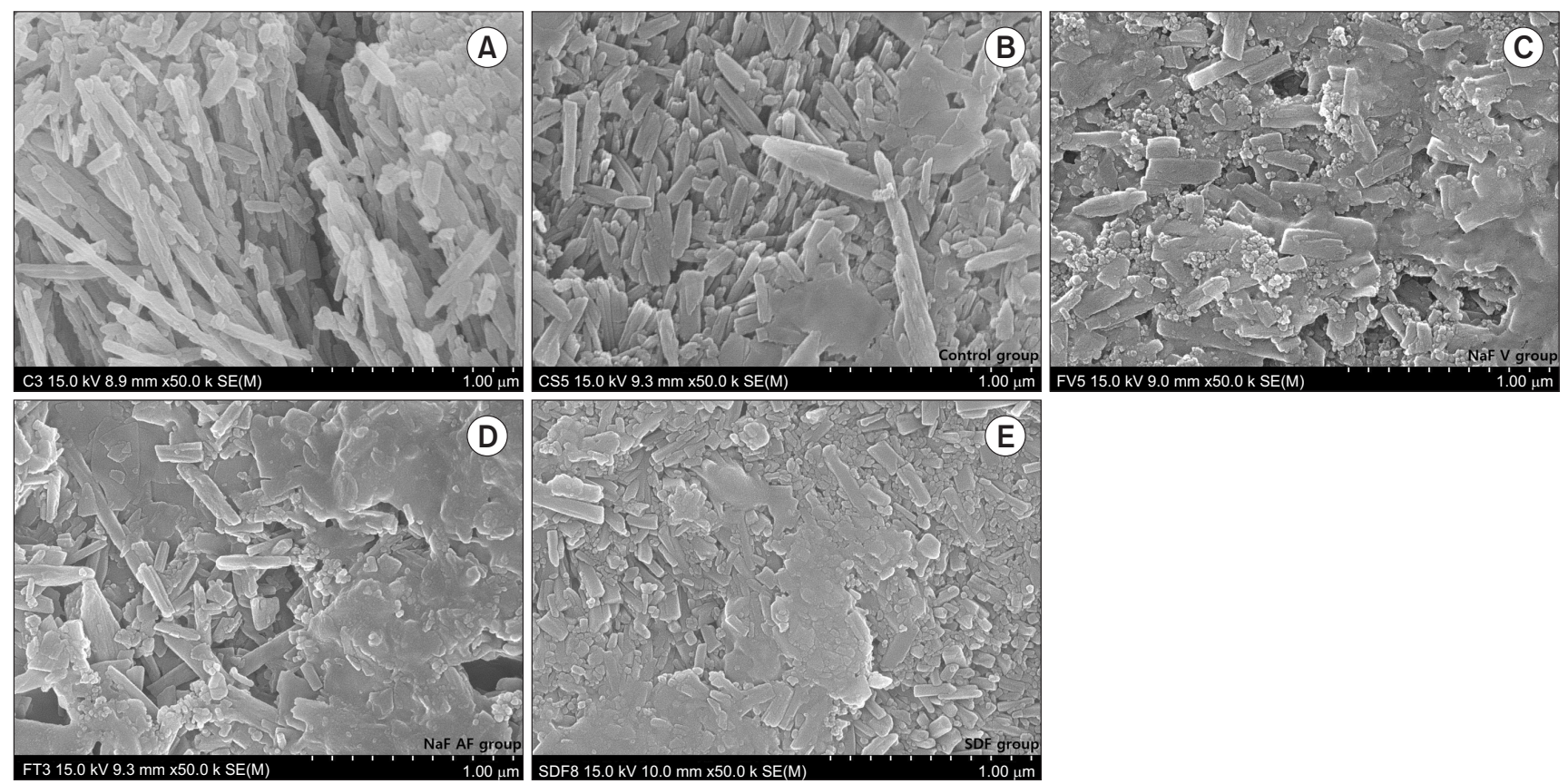

Fig. 5. The SEM images of microstructure of remineralized enamel surfaces in the deep initial carious lesion $(\times 10,000)$. (A) The crystal structure between the enamel rods was destroyed and micropores and mocrocracks were present. And the surface was more irregular than that of shallow initial carious lesion in the demineralized enamel specimen. (B) Amorphous crystals were partially deposited on the enamel rod in the control group. (C, D) In NaF V and the NaF AF groups, amorphous crystals were deposited and fused with the enamel rods. (E) And the surfaces were more irregular than that of shallow initial carious lesion. SDF group showed similar surface condition as the shallow initial carious lesion. NaF V, sodium fluoride varnish; $\mathrm{NaF}$ AF, sodium fluoride adhesive film; SDF, silver diamine fluoride.

$\mathrm{NaF} \mathrm{V}$ 군과 $\mathrm{NaF} \mathrm{AF}$ 군에서는 무정형 결정체가 법랑소주 상방에 침착되어 법랑소주와 융합된 모습을 보이고 있으며 대조군에 비해 더 부드러운 표면을 보였다. 얕은 우식병소에 비해 집소공 과 미세균열 같은 표면결함이 더 많이 관찰되었다(Fig. 5C, D). $\mathrm{SDF}$ 군은 무정형 결정체가 법랑소주 상방에 침착, 융합되어 탈 회된 표면의 대부분을 덮고 있으며 $\mathrm{NaF} \mathrm{V군과} \mathrm{NaF} \mathrm{AF군에} \mathrm{비}$ 해 더 부드러운 표면을 보였다. 얕은 우식병소의 재광화된 표면 과 별 차이를 보이지 않았다(Fig. 5E).

\section{Discussion}

이번 연구에서는 새로운 형태의 불소제제인 $\mathrm{NaF} \mathrm{AF}$ 와 $\mathrm{SDF}$ 의 초기 우식병소에 대한 재광화 효과를 정량적으로 분석하고, 기 존의 불소바니쉬 제제인 $\mathrm{NaF} \mathrm{V}$ 와 비교하고자 했다. 법랑질 표 면의 무기질 밀도 및 정상 법랑질 수준으로 재광화된 부피에 대 한 정량분석 결과, 세 가지 불소제제 중 SDF가 가장 크게 나타났 으며 SEM을 이용하여 관찰한 법랑질 표면도 가장 부드러운 상 태를 보여주어 재광화 효과가 가장 큰 것으로 나타났다. 이러한 결과는 두 가지 이유로 해석해 볼 수 있는데, 첫째로 $\mathrm{SDF}$ 가 5\% $\mathrm{NaF} \mathrm{V}$ 와 $5 \% \mathrm{NaF} \mathrm{AF}\left(22,600 \mathrm{ppm} \mathrm{F}^{-}\right)$에 비해 불소농도( 44,800 $\mathrm{ppm} \mathrm{F}^{-}$)가 더 높다는 것이다. 불소 적용방법이나 제형에 따라 약간의 차이는 있지만 일반적으로 불소농도가 높을수록 치질에 흡수되는 불소의 양이 많다는 사실은 여러 문헌에서 찾아볼 수 있다[14,15]. 둘째로 SDF는 액상형이어서 치질에서의 흐름성이 좋고 침투가 빨리 이루어지므로 타액의 씻김에 의한 손실이 적 은데 비해 바니쉬 형 제제는 치질로 침투하기 전 타액에 의해 씻 겨 내려갈 가능성이 더 크기 때문이다[14]. SDF는 이외에도 항 균효과 큰 은이온을 함유하고 있어 다종의 우식유발균으로 형 성되는 치면세균막의 성장을 방해하므로 다른 불소제제에 비 해 더 높은 우식 예방 및 정지효과를 나타낸다고 알려지고 있다 [16-18].

이번 연구에서 $\mathrm{NaF} \mathrm{AF}$ 가 $\mathrm{NaF} \mathrm{V}$ 와 유사한 재광화 효과를 보 여줌으로써 새로운 형태의 불소제제로의 임상적 적용 가능성을 보여주었다. 이전의 한 연구에서 $\mathrm{APF}$ 겔, $\mathrm{NaF} \mathrm{V,} \mathrm{NaF} \mathrm{AF}$ 의 구 강내 불소유리능력을 평가한 결과, 도포 후 6시간 경과된 시점 의 구강내 타액에서의 불소이온의 농도가 $\mathrm{APF}$ 겔이나 $\mathrm{NaF} \mathrm{V}$ 를 적용했을 때보다 $\mathrm{NaF} \mathrm{AF}$ 에서 더 높게 나왔다고 하였으며 그 이 유에 대해 치면에 더 오래 붙어있고 바니쉬형에 비해 타액에 의 한 씻김 현상이 적기 때문이라 하였다[19]. 또한 $\mathrm{NaF} \mathrm{AF}$ 는 $\mathrm{NaF}$ $\mathrm{V}$ 에 비해 적은 불소량을 사용하여 비슷한 재광화 효과를 낼 수 
있다는 장점을 가지고 있는데, $\operatorname{Kim}$ 등[7]은 $2.26 \% \mathrm{NaF}$ 를 함유 한 불소필름과 $2.26 \% \mathrm{NaF}$ 를 함유한 불소바니쉬(FluoroDose; Centrix Inc., Shelton, CT, USA)를 치아에 도포하였을 때, $\mathrm{NaF}$ $\mathrm{AF}$ 의 경우 가로 세로 $1 \mathrm{~cm}$, 세로 $12 \mathrm{~cm}$, 두께 $20 \mu \mathrm{m}$ 의 접착필 름을 상, 하악에 동시에 부착시키면 여기에 함유된 불소의 양은 $2.35 \mathrm{mg}$ 으로 상하악 $\mathrm{NaF}$ 를 함유한 바니쉬형 불소제제의 도포 량인 $6.79 \mathrm{mg}$ 에 비해 $1 / 3$ 에 해당되는 적은 양으로 똑같은 재광 화 효과를 발휘하였다고 보고한 바 있다.

$\mathrm{NaF} \mathrm{AF}$ 은 생체친화적인 친수성 고분자 소재를 이용한 약물 전달시스템으로, 치면에 접착력이 좋아 오랜 시간 동안 붙어있 으면서 불소이온을 서서히 유리시킬 수 있다. 또한 $\mathrm{NaF} \mathrm{AF}$ 는 바 니쉬형 불소제제보다 적용이 간편하고, 불쾌한 맛이 없으며 끈 적임이 없는 장점으로 상용화 가능성이 매우 높을 것으로 기대 된다.

본 실험에서는 초기 우식증의 깊이에 따른 불소제제의 재광 화 효과의 차이가 존재하는지 확인하고자 했는데, 인공우식병 소의 깊이를 2군으로 분류하기 위해 QLF-D를 사용하여 측정한 $\Delta \mathrm{F}$ 값을 기준으로 하였다. 선학들의 연구에서 $\Delta \mathrm{F}$ 값과 탈회 깊이 사이에는 상관계수가 -0.8 이상의 강한 음의 상관관계가 있다고 하였으며 선형회귀모델을 제시한 연구도 있는데[11,20], 이와 같은 자료를 바탕으로 본 실험에서 시편의 우식의 깊이를 계산 한다면 얕은 우식병소군은 평균 $\Delta \mathrm{F}$ 값이 $-23 \%$ 로 병소의 깊이는 $80 \mu \mathrm{m}$, 깊은 우식병소군의 평균 $\Delta \mathrm{F}$ 값은 $-45 \%$ 로 병소의 깊이 는 $160 \mu \mathrm{m}$ 정도였다. 초기 우식병소에서 불소제제의 재광화 효 과를 연구한 기존의 문헌에서 대부분 깊이가 $100 \mu \mathrm{m}$ 이하인 범 위의 우식병소를 대상으로 한 점을 고려했을 때, 본 실험의 160 $\mu \mathrm{m}$ 병소는 깊은 초기 우식병소에 해당된다고 볼 수 있다. Ten Cate 등[21,22]은 실험실 연구에서 불소치약 적용 후 $50 \mu \mathrm{m}$ 깊 이의 병소에서 $200 \mu \mathrm{m}$ 깊이의 깊은 병소보다 더 많은 재광화 가 이루어졌다고 하였다. 또한 상아질까지 연장된 우식병소에 $1000 \mathrm{ppm}$ 불소를 도포한 한 연구에서는 깊은 부위에서 재광화 가 관찰되었으나 그 정도는 매우 미미하다고 하였다.

본 연구에서는 $\mathrm{NaF} V$ 군과 $\mathrm{NaF} \mathrm{AF}$ 군에서는 우식의 깊이에 따른 재광화 정도의 차이가 통계학적으로 유의미하지 않았으 나, $\mathrm{SDF}$ 군에서는 깊은 우식병소에서 얕은 우식병소보다 더 많 은 재광화가 일어나는 것으로 나타났다. 이러한 결과는 $\mathrm{SDF}$ 가 액상이어서 침투깊이가 훨씬 크기 때문이라고 사료된다. 또한 $44,800 \mathrm{ppm}$ 불소가 함유된 $\mathrm{SDF}$ 가 22,600 ppm 불소가 함유된 $\mathrm{NaF} \mathrm{V}$ 군과 $\mathrm{NaF} \mathrm{AF}$ 군보다 더 높은 농도의 불소이온을 함유하고 있어 깊은 병소에서도 높은 재광화 효과를 보여주었다고 생각 된다. 그러나 이번 연구에서는 각 군간 불소농도가 다르고 제제 의 형태가 달라 $\mathrm{SDF}$ 의 높은 재광화 효과가 불소의 농도에 따른 차이인지 혹은 제제의 형태에 따른 차이인지는 규명하지 못하
였다. 따라서 앞으로 이와 같은 두 가지 요인 중 어떤 것이 결정 적인 영향을 미치는지에 대한 후속연구가 필요하다. 또한 필름 형태의 SDF에 대한 재광화 효과, 그리고 biofilm을 이용한 항균 효과에 대한 연구도 후속적으로 이루어져야 할 것으로 생각된 다.

이번 실험 결과는 $\mathrm{SDF}$ 는 기존의 다른 불소제제를 사용한 연 구들에서 유효한 효과가 관찰된 $100 \mu \mathrm{m}$ 이내 깊이의 초기 우식 증보다 더 깊은 병소에서 효과적인 재광화가 가능함을 보여주 고 있어, 임상적으로 불소제제에 의한 치아우식증 처치범위를 더 넓힐 수 있을 것으로 기대된다.

불소제제 도포 후 정상법랑질 수준으로 밀도가 회복된 부피 역시 SDF가 다른 두 불소제제보다 컸으며 특히 SDF군에서는 다른 군과는 달리 우식병소가 깊은 군에서 정상적인 법랑질 밀 도로 회복된 부피가 우식의 깊이가 얕은 군에 비해 더 크게 나타 났다. 이는 우식이 깊은 곳은 얕은 곳보다 상대적으로 탈회가 덜 되어 회복도 그만큼 더 많이 이루어진 것으로 해석할 수 있다.

본 실험에서 $\mathrm{SEM}$ 을 이용한 법랑질 표면분석결과에서도 얕은 우식병소군보다 깊은 우식병소군의 표면에 탈회로 인한 불규칙 한 결정구조가 더 많이 관찰되는 것을 확인할 수 있으며, 재광 화 후 표면상태도 깊은 우식 군에서 덜 부드러운 표면상태를 보 였다. Kim 등[11]은 초기 우식증의 탈회 정도에 따른 불소바니 쉬의 재광화를 통한 회복률에 대한 실험실 연구 결과, QLF-D의 $\Delta \mathrm{F}$ 값(\%)이 0 에서 $-10 \%$ 일 때 가장 높은 회복률(62.84\%)을 보였 으며 $\Delta \mathrm{F}$ 값이 감소할수록 회복률이 낮아지는 것으로 보고한 바 있다. 이러한 우식의 깊이에 따른 회복률의 차이는 구강 내 환경 에서 우식의 진행 또는 정지에 영향을 미칠 수 있을 것으로 생각 된다.

이번 실험에서 불소제제의 재광화 효과를 평가하기 위해 micro-CT를 활용하여 치아 경조직의 미세한 무기질 변화를 평 가하였는데, 이 방법은 비침습적 방법이면서 $1 \%$ 이하의 오차율 과 5-30 $\mu \mathrm{m}$ 범위의 해상도를 갖는 장점이 있어 최근에는 치질 의 무기질 분석에도 활용되고 있다[23,24]. 또한 micro-CT를 이용한 치아조직의 무기질 농도 관찰 연구는 동일한 시편을 재 광화 전과 후의 밀도 변화를 종적으로 평가하는 동시에, 시편의 전체 영역을 대상으로 미세한 무기질 농도의 변화를 정량적으 로 평가할 수 있어, 서로 다른 시편으로 일부분만을 평가하던 기 존의 분석방법에 비해 보다 더 정확한 정보를 제공할 수 있다.

본 연구의 한계점은 구강 내 타액 환경을 정확히 제공하지 못 해 불소의 치면에서의 접착과 씻김 현상을 생체 내에서처럼 재 현할 수 없었다는 점이며 또한 법랑질에 한정하여 재광화 효과 를 평가하였다는 점이다. 앞으로 기존의 불소바니쉬 제제는 물 론 $\mathrm{SDF}$ 와 불소접착필름 등 새로 개발된 불소제제의 상아질에서 의 우식예방이나 차단효과에 대해서도 연구가 함께 이루어져야 
할 것으로 생각된다.

이번 연구 결과를 종합하면 $\mathrm{SDF}$ 의 재광화 효과가 $\mathrm{NaF} \mathrm{V}$ 와 $\mathrm{NaF} A$ 군에 비해 크게 나타났으며 특히 더 깊은 깊은 우식 병소 에서 재광화 효과의 차이가 더 컸다. $\mathrm{NaF} \mathrm{V}$ 와 $\mathrm{NaF} \mathrm{AF}$ 는 재광 화 효과의 차이가 없었다. 따라서 $\mathrm{SDF}$ 는 기존의 얕은 법랑질 초 기우식증에 한정되었던 불소제제의 적용범위를 더 확대시킬 수 있을 것으로 기대된다.

\section{Acknowledgements}

This study was supported by research fund from Chosun University, 2019.

\section{Conflicts of Interest}

The authors declare that they have no competing interests.

\section{ORCID}

\author{
Mi-Ri Kim \\ https://orcid.org/0000-0001-8730-467X \\ Sang-Ho Lee \\ https://orcid.org/0000-0003-2513-6871 \\ Nan-Young Lee \\ https://orcid.org/0000-0002-4738-9389 \\ Myeong-Kwan Jih \\ https://orcid.org/0000-0001-9579-076X \\ Ji-Woong Kim \\ https://orcid.org/0000-0002-7561-8361 \\ Won-Seok Choi \\ https://orcid.org/0000-0003-2283-2601
}

\section{References}

1. Featherstone JDB. Dental caries: a dynamic disease process. Aust Dent J 2008;53:286-291. doi: 10.1111/j.18347819.2008.00064.x.

2. Paula ABP, Fernandes AR, Coelho AS, Marto CM, Ferreira MM, Caramelo F, do Vale F, Carrilho E. Therapies for white spot lesions- a systematic review. J Evid Based Dent Pract 2017:17:23-38. doi: 10.1016/j.jebdp.2016.10.003.

3. Chu CH, Lo E. Uses of sodium fluoride varnish in dental practice. Ann R Australas Coll Dent Surg 2008;19:58-61.

4. Al Dehailan L, Lippert F, González-Cabezas C, Eckert
GJ, Martinez-Mier EA. Fluoride concentration in saliva and biofilm fluid following the application of three fluoride varnishes. J Dent 2017;60:87-93. doi: 10.1016/ j.jdent.2017.03.005.

5. Wright JT, White A. Silver diamine fluoride: changing the caries management paradigm and potential societal impact. N C Med J 2017;78:394-397. doi: 10.18043/ ncm.78.6.394.

6. Burgess JO, Vaghela PM. Silver diamine fluoride: a successful anticarious solution with limits. Adv Dent Res 2018;29:131-134. doi: 10.1177/0022034517740123.

7. Kim MJ, Lee SH, Lee NY, Lee IH. Evaluation of the effect of PVA tape supplemented with $2.26 \%$ fluoride on enamel demineralization using microhardness assessment and scanning electron microscopy: in vitro study. Arch Oral Biol 2013;58:160-166. doi: 10.1016/j.archoralbio.2012.06.015.

8. Lee SH, Lee NY, Lee IH. Clinical evaluation of the efficacy of fluoride adhesive tape (F-PVA) in reducing dentin hypersensitivity. Am J Dent 2013;26:143-148.

9. Delbem ACB, Bergamaschi M, Sassaki KT, Cunha RF. Effect of fluoridated varnish and silver diamine fluoride solution on enamel demineralization: pH-cycling study. J Appl Oral Sci 2006;14:88-92. doi: 10.1590/s167877572006000200005.

10. Mohammadi N, Farahmand Far MH. Effect of fluoridated varnish and silver diamine fluoride on enamel demineralization resistance in primary dentition. J Indian Soc Pedod Prev Dent 2018;36:257-261. doi: 10.4103/JISPPD. JISPPD_4_18.

11. Kim HE, Kwon HK, Kim BI. Recovery percentage of remineralization according to severity of early caries. Am J Dent 2013;26:132-136.

12. Alammari MR, Smith PW, de Josselin de Jong E, Higham SM. Quantitative light-induced fluorescence (QLF): a tool for early occlusal dental caries detection and supporting decision making in vivo. J Dent 2013;41:127-132. doi: 10.1016/j.jdent.2012.08.013.

13. Kim MH, Lee SH, Lee NY. Diagnosis of early dental caries with dye-enhancing quantitative light-induced fluorescence (QLF). J Korean Acad Pediatr Dent 2015;42:218-225. doi: 10.5933/JKAPD.2015.42.3.218.

14. Altenburger MJ, Schirrmeister JF, Lussi A, Klasser M, Hellwig E. In situ fluoride retention and remineralization of incipient carious lesions after the application of different concentrations of fluoride. Eur J Oral Sci 2009;117:58-63. doi: 10.1111/j.1600-0722.2008.00585.x.

15. Shah S, Bhaskar V, Venkataraghavan K, Choudhary P, Ganesh M, Trivedi K. Efficacy of silver diamine fluoride as an antibacterial as well as antiplaque agent compared to fluoride varnish and acidulated phosphate fluoride gel: an in vivo study. Indian J Dent Res 2013;24:575-581. doi: 10.4103/0970-9290.123374.

16. Yu OY, Mei ML, Zhao IS, Li QL, Lo ECM, Chu CH. Reminer- 
alisation of enamel with silver diamine fluoride and sodium fluoride. Dent Mater 2018;34:e344-e352. doi: 10.1016/ j.dental.2018.10.007.

17. Mei ML, Lo ECM, Chu CH. Clinical use of silver diamine fluoride in dental treatment. Compend Contin Educ Dent 2016;37:93-98; quiz100.

18. Mei ML, Li QL, Chu CH, Lo ECM, Samaranayake LP. Antibacterial effects of silver diamine fluoride on multi-species cariogenic biofilm on caries. Ann Clin Microbiol Antimicrob 2013;12:4. doi: 10.1186/1476-0711-12-4.

19. Lee KY, Lee SH, Lee NY. Evaluation of fluoride-releasing capacity from polyvinyl alcohol polymer tape supplemented with $\mathrm{NaF}$ in oral cavity. J Korean Acad Pediatr Dent 2013;40:89-97. doi: 10.5933/JKAPD.2013.40.2.89.

20. Wu J, Donly ZR, Donly KJ, Hackmyer S. Demineralization depth using QLF and a novel image processing software. Int J Dent 2010;2010:958264. doi: 10.1155/2010/958264.

21. ten Cate JM, Exterkate RAM, Buijs MJ. The relative efficacy of fluoride toothpastes assessed with pH cycling. Caries Res 2006;40:136-141. doi: 10.1159/000091060.

22. ten Cate JM. Remineralization of deep enamel dentine caries lesions. Aust Dent J 2008;53:281-285. doi: 10.1111/ j.1834-7819.2008.00063.x.

23. Swain MV, Xue J. State of the art of micro-CT applications in dental research. Int J Oral Sci 2009;1:177-188. doi: 10.4248/IJOS09031.

24. Neboda C, Anthonappa RP, King NM. Tooth mineral density of different types of hypomineralised molars: a microCT analysis. Eur Arch Paediatr Dent 2017;18:377-383. doi: 10.1007/s40368-017-0306-8. 